\title{
Estereotipos y contraestereotipos del papel de la mujer en la Gran Guerra. Experiencias femeninas y su reflejo en el cine
}

\author{
Estela BERNAD MONFERRER \\ Universitat Jaume I, Castellón \\ bernad@uji.es \\ Magdalena Mut CAMACHO \\ Universitat Jaume I, Castellón \\ magda.mut@uji.es \\ César FERNÁNDEZ FERNÁNDEZ \\ Universitad Jaume I, Castellón \\ cesar.fernandez@uji.es
}

Recibido: 14 de mayo de 2013

Aceptado: 10 de julio de 2013

\section{Resumen}

La mujer ha sido la gran olvidada por parte de la ciencia de la historia. Durante siglos los estudiosos han relatado los hechos históricos en clave masculina, ya que eran los hombres quienes los escribían, produciéndose un resultado extraño, pues la población mundial siempre ha estado conformada por hombres y mujeres. Como decía Virginia Wolf, la no presencia de las mujeres en la historia, producía una historia "rara, irreal, desnivelada" (Ferrús, 2010: 65) y como señalaba Lerner (1981: 22):

"Hay mujeres en la Historia y hay hombres en la Historia, y sería de esperar que ningún planteamiento histórico de un período determinado pudiera haberse escrito sin tratar de las acciones e ideas tanto de hombres como de mujeres"

Con este trabajo pretendemos realizar una reflexión acerca de dos realidades que coinciden con el desarrollo de la Primera Guerra Mundial: por un lado, el cambio sociológico alrededor del papel de la mujer en el espacio público y por otro el desarrollo de un nuevo medio para poder construir la historia, el cine. En este último caso, el cine, como cualquier otro arte, no está exento de la pátina creativa y no objetiva de su autor/a, pero también nos permite contextualizar a sus protagonistas e inmiscuirnos en su intimidad, suponiendo una visión amplia de los mismos en su contexto total, sin fisuras, ayudando a conocer realidades, que de otra manera quedarían en el olvido.

Por eso, con este artículo pretendemos realizar una aproximación a la transformación que se produjo en el rol de la mujer y su participación en el espacio público a partir de ese periodo histórico, y como su tratamiento cinematográfico, tanto el coetáneo a la gran contienda como el posterior inspirado en su contexto, nos permiten ver el reflejo de esos cambios que sirvieron para asentar una nuevo modelo de mujer precursor de la mujer occidental actual.

Palabras clave: Estereotipo; género; Primera Guerra Mundial; cine; feminismo; cultura patriarcal. 


\title{
Stereotypes and counterstereotypes of the role of women in the Great War. Female experiences and their reflection in the cinema.
}

\begin{abstract}
The woman has been forgotten by the science of history. For centuries scholars have related the historical events in men key, since were the men who wrote them, producing a strange result, because the world population has always included men and women. As Virginia Woolf said, the non-presence of women in history, produced a story "weird, unreal, uneven" (Ferrus: 2010: 65) and as noted by Lerner (1981: 22):

There are women in history and there are men in history, and one would expect that no any historical approach in a given period could have been written without discussing actions and ideas of both men and women.

In this paper we make a reflection about two realities coinciding with the development of the First World War: first, the sociological change around the role of women in public places and second, the development of a new medium to construct history, cinema.

So, with this article we make an approach to the transformation that occurred in the role of women and their participation in public space from that historical period, and as a film treatment, both contemporary with the great contest as inspired subsequent context, allow us to see the reflection of the changes that served to lay a new female model precursor of modern woman.
\end{abstract}

Key words: Stereotypical gender; World War; cinema; feminism; patriarchal culture.

\section{Referencia normalizada:}

Bernad Monferrer, E., Mut Camacho, M. y Fernández Fernández, C. (2013) Estereotipos y contraestereotipos del papel de la mujer en la Gran Guerra. Experiencias femeninas y su reflejo en el cine. Historia y Comunicación Social. Vol. 18, págs. 169-189.

Sumario: 1. Introducción. 2. EL tratamiento cinematográfico de la primera guerra mundial. 3. Estereotipos y contraestereotipos femeninos: el antes y el después de la Gran Guerra. 3.1. Concepto de estereotipo y contraestereotipo de género. 3.2. Estereotipos de género femenino anteriores a la Gran Guerra: el siglo XIX. 3.3. La Primera Guerra Mundial y su influencia en las estereotipaciones de género. 4. Experiencias contraestereotípicas femeninas en el contexto de la Gran Guerra. 5. Estereotipos femeninos en el cine. Especial referencia a las estereotipaciones femeninas en las películas sobre la Primera Guerra Mundial. 6. Conclusiones. 7. Bibliografía.

\section{Introducción}

La mujer ha sido la gran olvidada por parte de la ciencia de la historia. Durante siglos los estudiosos han relatado los hechos históricos en clave masculina, ya que eran los hombres quienes los escribían, produciéndose un resultado extraño, pues la población mundial siempre ha estado conformada por hombres y mujeres. Como decía Virginia Wolf, la no presencia de las mujeres en la historia, producía una historia "rara, irreal, desnivelada" (Ferrús, 2010: 65) y como señalaba Lerner (1981: 22):

Hay mujeres en la Historia y hay hombres en la Historia, y sería de esperar que ningún planteamiento histórico de un período determinado pudiera haberse escrito sin tratar de las acciones e ideas tanto de hombres como de mujeres. 
La Primera Guerra Mundial (PGM), supuso un antes y un después en el tratamiento sociológico de la mujer. Las especiales circunstancias que se produjeron en ese momento de la historia comportaron cambios fundamentales que propiciaron la incorporación paulatina de las féminas al mercado laboral y por ende, al espacio público que hasta aquella fecha era territorio exclusivo del varón. Esta contienda, cambió la visión romántica que hasta la fecha se tenía de las guerras, con sus héroes y victorias. La globalización del conflicto, la aparición de una potente industria bélica generadora de intereses, las movilizaciones generales obreras y de las clases menos pudientes así como la incorporación masiva de la mujer al mercado laboral, supuso un terremoto económico de gran dimensión y que coincidió en el tiempo con el inicio de la industria del cine.

La Gran Guerra supuso para el género femenino la salida del espacio doméstico para ocupar aquellos puestos de trabajo que habían sido abandonados por los hombres tras marchar a las trincheras. Además, la confrontación acarreó la necesidad de nuevos puestos de trabajo para fabricar armamento y otros productos demandados desde primera línea. Esto hizo que las mujeres realizasen tareas tradicionalmente masculinas como conducir camiones o autobuses, montar armas y manipular mercancías peligrosas, como balas, bombas y proyectiles entre otras. Pero las mujeres también vivieron la contienda en primera línea, para servir en los hospitales militares, ejercer el voluntariado o realizar otro tipo de trabajos desarrollados en el frente. Esta incorporación masiva de las mujeres a la vida laboral representó una experiencia sin precedente de libertad y responsabilidad así como la exaltación de papeles tradicionalmente reservados a su sexo y que hasta ese momento no habían sido apreciados (enfermeras, cocineras....).

Por otro lado, es en ese periodo histórico cuando se produce los albores del cine como industria, coincidiendo con el desarrollo de la gran contienda, y sirviendo de laboratorio para el surgimiento de un nuevo género: "el cine bélico". En este sentido, el director David W. Griffith, viajó hasta Europa donde pudo observar desde la primera línea de batalla, cómo la realidad no era tan atractiva ni interesante como se vislumbraba en la retaguardia. Fue Griffith quien para adaptarlo al gusto del público, mezcló material rodado en el frente occidental con reconstrucciones filmadas en los estudios, de aquí surgió la película "Corazones del mundo" (1918) y el inicio de este tipo de género cinematográfico (Romero, 2013: 25).

Coincidiendo con ese momento, el cine se va a convertir en un arte narrativo, es decir, va a contar historias y por otro lado va a conseguir que el espectador se sumerja en ellas, deje influir sus emociones, sus deseos, sus afectos y sus odios en un universo de ficción (Benet, 2010: 285). Y aunque la historiografía científica durante décadas no apreció este medio como instrumento de apoyo, considerándolo lejano a la verdad histórica, la realidad nos ha demostrado, que en muchos casos el cine se ha convertido en la única fuente capaz de relatar datos "olvidados...", ayudando a recordar, muchas veces desde la ficción, y en pocos trazos, incontables aspectos a tener en cuenta (paisajes, indumentaria, marco-sociopolítico, etc.) (Romero, 2013: 20). 
Con este trabajo pretendemos realizar una reflexión acerca de dos realidades que coinciden con el desarrollo de la PMG: por un lado, el cambio sociológico alrededor del papel de la mujer en el espacio público y por otro el desarrollo de un nuevo medio para poder construir la historia, el cine. En este último caso, el cine, como cualquier otro arte, no está exento de la pátina creativa y no objetiva de su autor/a, pero también nos permite contextualizar a sus protagonistas e inmiscuirnos en su intimidad, suponiendo una visión amplia de los mismos en su contexto total, sin fisuras, ayudando a conocer realidades, que de otra manera quedarían en el olvido.

Por eso, con este artículo pretendemos realizar una aproximación a la transformación que se produjo en el rol de la mujer y su participación en el espacio público a partir de ese periodo histórico, y como su tratamiento cinematográfico, tanto el coetáneo a la gran contienda como el posterior inspirado en su contexto, nos permiten ver el reflejo de esos cambios que sirvieron para asentar una nuevo modelo de mujer precursor de la mujer occidental actual.

\section{El tratamiento cinematográfico de la I Guerra Mundial}

A la hora de analizar las películas que sobre la PGM recoge el séptimo arte, descubrimos un hecho bastante constante: la sombra de la Segunda Guerra Mundial (SGM). En primer lugar, no encontramos la misma cantidad de producción cinematográfica sobre la Gran Guerra como sobre el segundo conflicto mundial. Y también podemos constatar como muchas películas rodadas sobre aquel acontecimiento, fueron eclipsadas por versiones posteriores, que enmarcaron su desarrollo en la segunda contienda.

Esto es debido a varios factores, entre los que podemos destacar los siguientes:

1. Coincidencia del primer conflicto bélico con el surgimiento de la industria cinematográfica. Ciertamente, la PGM coincide con los albores de esta industria, principalmente en Estados Unidos. Sin embargo, veinte años después, este sector económico ya se encontraba consolidado. Por este motivo, muchas películas que trataron el primer conflicto fueron contemporáneas a la propia guerra, por lo que muchas de ellas se rodaron en blanco y negro y sin sonido, y el posterior desarrollo del audio en el cine, lo hizo mucho más atractivo produciendo el arrinconamiento de gran parte de la anterior producción no sonora.

2. Los propios escenarios donde se desarrollaron las batallas, que en el caso de la PGM prácticamente se centraba en kilómetros y kilómetros de trincheras, espacio poco atractivo y estático. Los escenarios de la SGM eran más ágiles, debido a las armas ligeras y a los continuos movimientos de las líneas de ataque, lo que hizo que el desarrollo de la narración fuese mucho más seductor.

3. El mundo civil en las narraciones de los conflictos. Mientras que en la PGM el mundo civil es casi irrelevante, éste es el protagonista de muchas de las obras de la SGM, como es el caso de la resistencia, el genocidio judío, la cultura nazi etc. que ayudan a ampliar y atraer las temáticas y los públicos objetivos. 
4. La simbología de la SGM. La estética nazi producía un atractivo contradictorio de placer estético y horror conceptual (Romero, 2013: 28). Esta misma simbología ayuda a definir a los héroes de los villanos, quedando claramente diferenciados, mientras que en la PGM esta diferencia aparece lejana, desdibujada y poco definida.

De esta forma, encontramos que grandes películas que recogieron la temática del primer gran conflicto de carácter mundial, apenas son recordadas, mientras que sus versiones adaptadas a la SGM, han cosechado éxito y son las que han quedado en la memoria. Pese a los inconvenientes descritos, existen más de cien películas que con mayor o menor éxito de taquilla, han tratado esta temática, e incluso el primer film en conseguir un Oscar a la mejor película fué "Alas" (1927) de William A. Wellman, desarrollada en pleno conflicto bélico de la PGM, y que recoge una de las más impactantes escenas bélicas del cine clásico, la de Saint-Muhiel, decisiva en esta contienda.

\section{Estereotipos y contraestereotipos femeninos: El antes y el después de la Gran Guerra}

El siglo XX es sin lugar a dudas el siglo de la mujer. Pero aunque la incorporación paulatina de ésta al espacio público, está estrechamente vinculada al principio de igualdad y este principio aparece ligado a su vez, a los primeros documentos revolucionarios (francés, norteamericano) surgidos a finales del siglo XVIII y principios del XIX, la proclamación constitucional específica del principio de igualdad de mujeres $\mathrm{y}$ hombres es un elemento ciertamente tardío que no se produce hasta la segunda mitad del S. XX.

De esta manera, una vez rotas las cadenas victorianas enraizadas a lo largo del siglo XIX y que anclaban a las féminas al ámbito privado y familiar y a aquellas concepciones que consideraban que las mujeres no eran sujetos sociales porque sus roles eran considerados naturales, el movimiento feminista surge como un movimiento internacional y cohesionado que lucha por cuestiones fundamentales como el derecho al voto, la división sexual de las tareas y la equiparación salarial, y una preocupación constante por las cuestiones de la maternidad (aborto, medidas de anticoncepción, higiene).

\subsection{Concepto de estereotipo y Contraestereotipo de Género}

Este largo camino hacia la equiparación de los sexos, va llenándose de estereotipos propios de la construcción cultural del género que se van estableciendo según el constructo social anclado en un lugar y tiempo determinado. Se transmiten de generación en generación a través del proceso de socialización, es decir, del proceso de culturización que adapta e integra a las personas en la sociedad. El proceso de socialización ejerce una influencia en las formas de actuar, de pensar y de sentir (Bustos, 2004: 24). 
Cuando hablamos de estereotipos de género, nos estamos refiriendo a aquel conjunto de ideas simples, previas, irracionales que se atribuyen a las personas en función de su adscripción sexual, prescribiendo características definitorias sobre su manera de ser -su identidad- y de comportarse -su rol social-, de acuerdo a la prescripción de género, como mecanismo activador de la ideología patriarcal (Bernad, 2010: 304 ). En este sentido se adscriben una serie de características, atributos o rasgos de personalidad con una fuerte carga simbólica que señalan que la femineidad es propia de las mujeres y la masculinidad, propia de los varones, asignándose roles y relaciones de poder distintas en función de esta división y dando mayor prestigio y estatus a las acciones realizadas por los varones que a las acciones realizadas por las mujeres.

Los estereotipos de género se refieren al conjunto de creencias, pensamientos o representaciones acerca de lo que significa ser hombre o mujer, incidiendo en esferas tales como: apariencia física, intereses, rasgos psicológicos, relaciones sociales, formas de pensar, de percibir y de sentir, ocupaciones etc. (Bustos, 2004: 25).

Abundando en este pensamiento, Cobo (1995) señala que «el género es una construcción cultural que se ha plasmado históricamente en forma de dominación masculina y sujeción femenina. Esta jerarquización sexual se ha materializado en sistemas sociales y políticos patriarcales». Apoyándonos en esta definición, destacaríamos que esta construcción cultural se ha ido forjando a lo largo de la historia, entorno a una serie de componentes de género: el rol, o componente sociológico; la identidad sexuada, o componente psicológico, y el estatus o componente político, que han venido reproduciendo elementos funcionales como los estereotipos de género, que determinan la reproducción social de la desigualdad entre ambos géneros.

Los estereotipos son conceptos estáticos y universalistas que integran a las personas en un grupo con ciertos rasgos que deben reunir por el sólo hecho de formar parte del mismo. Es decir, se trata de una imagen estructurada y aceptada por la mayoría de las personas como representativa de un determinado colectivo. Esta imagen se forma a partir de una concepción estática sobre las características generalizadas de los miembros de esa comunidad. Es una representación inalterable que es compartida por la sociedad.

De esta manera todas las construcciones contrarias a esta universalización hierática y aceptada mayoritariamente por la sociedad se convierten en contraestereotipos, es decir, la presentación de una versión opuesta a la percepción estereotipada, a fin de demostrar que esta última no es verdad absoluta. Se trata de una representación de una versión opuesta al estereotipo que se plantea y supone en la mayoría de los casos un nadar contracorriente a las reglas socialmente establecidas.

Así, el contraestereotipo, rompe la pacífica y aceptada apariencia para transgredir en las construcciones sociales y en muchos casos para comenzar nuevos modelos que poco a poco se irán aceptando por la sociedad. 


\subsection{Estereotipos de género femenino anteriores a la Gran Guerra: El Siglo XIX}

En la conformación de estereotipos de género hay un antes y un después al desarrollo de la Gran Guerra. La sociedad, desde siempre, ha atribuido diferencias, en cuanto a cualidades y características psicológicas, al varón y a la mujer. Sus papeles culturales han venido determinados por las diferencias sexuales, por lo que las funciones que ambos desarrollaban en la sociedad no eran intercambiables. Esto a su vez se traducía en una división sexual del trabajo, consistente en la diferenciación que se hacía sobre las actividades que deben realizar unos y otras, adjudicando diferentes espacios en función del sexo (Elosegui, 1998: 80). Quedando claro que la cultura ha ido modelizando a las mujeres para que respondan a las expectativas de una sociedad patriarcal.

El siglo XIX era un siglo patriarcal en donde se ensalzaban comportamientos tradicionalmente atribuidos al varón, como el valor, la aventura, el honor. Es el siglo de las grandes colonias y los grandes aventureros y en donde el espíritu victoriano impregnaba los espacios culturales. Antes de la Gran Guerra, el reconocimiento social de la mujer sólo se conocía atendiendo a dos conceptos: el espacio privado y su alteridad, es decir, su ser "para el otro" que producía como decía Beauboir (1999: 478) confusión con su mismo ser.

En estas circunstancias, pese a los postulados revolucionarios con los que irrumpe el siglo XIX que hicieron caer instituciones y barreras en la construcción de las sociedades occidentales, el papel social de la mujer se constreñía a un universo reduccionista marcado por la explotación doméstica, las representaciones ideológicas y artísticas de cómo "debía ser" y cómo "debía comportarse" y su falta de instrucción pública (la mayoría de las mujeres eran analfabetas) (Perrot y Fraisse, 1994).

Es decir, la revolución introdujo derechos pero éstos no se aplicaron a las mujeres. Se siguió dejándolas al margen del derecho, excluyéndolas del voto, de la educación y de cualquier derecho laboral, no pudiendo acceder a puestos cualificados (Anaud-Duc, 1994: 91). Es más, en el siglo XIX, los juristas trataron de legitimar la desigualdad de tratamiento según el sexo con la afirmación de que las mujeres, en el fondo, "desean ser protegidas contra sí mismas" y dejando entrever la posibilidad de reformas a favor de la igualdad de derechos entre sexos, "cuando las mujeres estén en condiciones de regir asuntos...". En aquella época, el estereotipo burgués de mujer era aquel que la representaba con una imagen de dulzura y compasión, construida de acuerdo al modelo de la madre de familia burguesa.

El imaginario decimonónico establecía los estereotipos de acuerdo a las concepciones arquetípicas que se plasmaban en las imágenes de la época. Tres eran los arquetipos femeninos que poblaron la imaginación del siglo XIX: la mujer Virgen, la mujer seductora y la musa (Higonnet, 1994: 272), y aunque en este siglo se produce una evolución en las imágenes femeninas literarias y artísticas de lo religioso a lo profano, mostrando escenas familiares y cotidianas, estas todavía ayudaron a marcar más si cabe, los estereotipos establecidos entre mujeres y hombres. 
Durante la década de los sesenta del siglo XIX hubo una fuerte representación de imágenes femeninas en el ámbito doméstico y familiar, en los que se insistía en los roles femeninos de hijas castas, esposas y madres. La ideología burguesa de aquella época situaba con toda firmeza las mujeres virtuosas en el hogar (Higonnet, 1994: 299) y la sociedad tradujo esta visión diferenciando claramente los sexos y sus roles.

Esto se llevó hasta extremos máximos, siendo en esta época cuando más se diferenciaron las indumentarias femeninas de las masculinas. De hecho, los pantalones simbolizaban la masculinidad y usarlos significaba aspirar a obtener derechos propios de los hombres, lo cual fue objeto de posicionamiento ideológico como en el caso de George Sand (Amandine Aurore Lucile Dupin, Condesa de Dudebaunt, 1804-1876), cuyo atuendo masculino con el que se paseaba por París, manifestó con radicalidad su planteamiento con más énfasis que su seudónimo de varón e incluso el contenido trasgresor de su obra escrita. Sand manifestaba que "el genio no tiene sexo". George Sand, encarnó un contraestereotipo de la mujer victoriana, que se ha repetido en la historia por otras mujeres para poder aspirar a entrar en el espacio público ocupado por los varones (Juana de Arco, Concepción Arenal...).

Los contraestereotipos que rompen y chocan con los constructos sociales establecidos, introducen los cambios que mejoran la sociedad.

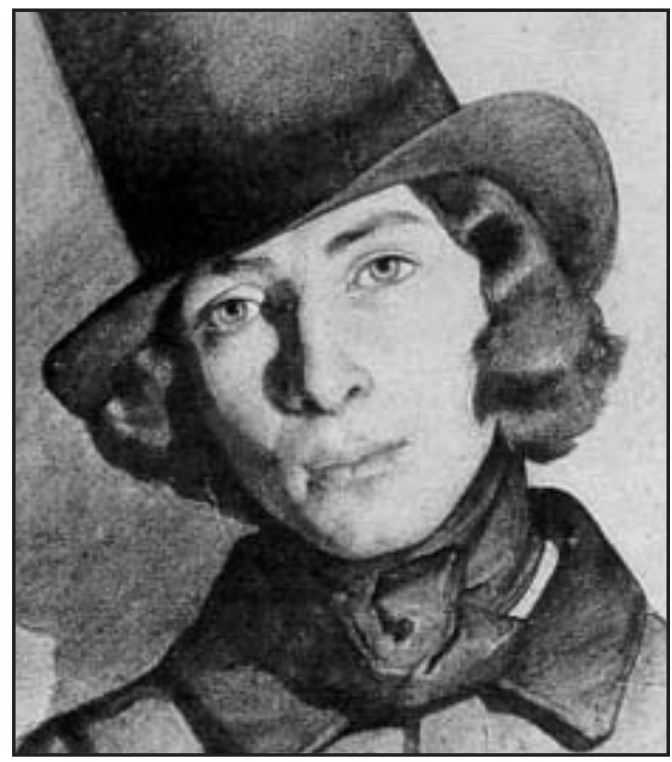

Frente a la mujer angelical, el otro estereotipo de mujer decimonónico es la mujer fatal, llamada por los románticos "mujer turbia" o "mujer contaminada", representa el modelo de mujer transposición femenina del héroe byroniano (Camps, 2011: 1). La fascinación hacia lo femenino se percibe siempre como un elemento diabólico, y donde el ideal erótico se combina con lo exótico, a menudo de carácter orientalizante. Por tal motivo, el escenario bizantino resulta recurrente en la representación de la "femme fatale", tanto en la literatura como en las artes plásticas. La mezcla de voluptuosidad y misticismo, tan característica en el fin de siglo, corresponde, de hecho, al éxtasis del exotista, siendo el exotismo una proyección fantástica de una necesidad sexual, como se puede apreciar en múltiples ocasiones en Th. Gautier o en G. Flaubert, entre otros.

Mata Hari (Margarita Zeller) se valió de su exótico físico y de su conocimiento sobre las danzas javanesas eróticas para convertirse en una de las cortesanas más famosas de la primera década del siglo XX. 
La mujer fatal se representa con gran sensualidad y experiencia sexual. En su representación evoca los placeres prohibidos y sacrílegos de un erotismo perverso que trae la perdición al hombre: voz profunda e insinuante, mirada, fría y cruel, desdén, ironía, ira, enigmática sonrisa, o sádica risa, palidez de su rostro y boca singularmente roja. Se halla a menudo envuelta en rosas sensuales, cubierta de perfumes y joyas, y rodeada de una decoración suntuosa y bizantina, exuberante como ella misma: es una diosa. Destaca por su movimiento (por contraste con el estatismo de las representaciones de la "femme fragile"), por lo que a menudo se combina su representación con la imagen de la serpiente, el fuego o la danza. (Camps, 2011).

\subsection{La Primera Guerra Mundial y su influencia en las estereotipaciones de género}

El final del siglo XIX se caracterizó por la entrada en el escenario social de las luchas feministas que reclamaron los derechos enunciados y no aplicados por los principios revolucionarios democráticos. El derecho al trabajo y en el trabajo, la lucha por la autonomía económica fundamentalmente reclamada por las mujeres burguesas solteras, el derecho al voto y a la educación entre otras cuestiones, son exigidos por grupos de mujeres burguesas que han tenido acceso a la instrucción.

Frente a este panorama la concepción del trabajo como algo natural para el hombre y anormal para las mujeres se modifica durante la Gran Guerra suponiendo un cambio en las relaciones entre los sexos y una emancipación de las mujeres inigualable hasta la fecha. La reestructuración total de la industria civil a la militar y la marcha de los hombres en edad laboral al frente (el hecho de movilizar enormes ejércitos provocó que la retaguardia quedase huérfana), obligó la incorporación de la mano femenina a la industria, no tan solo en los puestos menos cualificados, sino también en los técnicos y especializados, que las mujeres desempeñaron tan bien (si no mejor) que los hombres.

Además, las mujeres por necesidad desarrollaron trabajos que tradicionalmente eran masculinos (camareras, deshollinadoras, conductoras de tranvías, de camiones y otros vehículos, obreras fabriles....).

Por otro lado, durante la guerra la prensa y la literatura reconocen el trabajo tradicional de las mujeres, poniendo en valor figuras como la enfermera, la madrina de guerra o la dama de caridad, es decir, reviven los mitos de la mujer salvadora y consoladora, la mujer ángel y madre. La mujer blanca, asociada a la virginidad, a la madre a la princesa de los cuentos...

Tras la guerra, fue muy difícil hacer retornar a la mujer a la vida privada e íntima del hogar y aunque todavía quedaba un largo camino por la igualdad salarial, reniegan del papel anterior en el ámbito privado y exigen el derecho al trabajo y su integración y emancipación social. Pese a ello, en 1919 más de 650.000 mujeres están desempleadas en la Inglaterra post bélica (Sotelo, 2011: 3). 
Las mujeres que tenían oportunidad de viajar, de leer, y acceso a la cultura, adoptaron actitudes y comportamientos que reñían con el ideal virginal y ascético de mujer victoriano y patriarcal e imponen la sofisticación en el vestir, el afán de lujo, el flirt, la coquetería, los deportes, etc. Las inquietudes intelectuales y artísticas de este segmento social, frecuentemente encontraron resistencias, censuras y burlas tanto de la prensa católica como de sectores tradicionales, más que todo masculinos, de la sociedad.

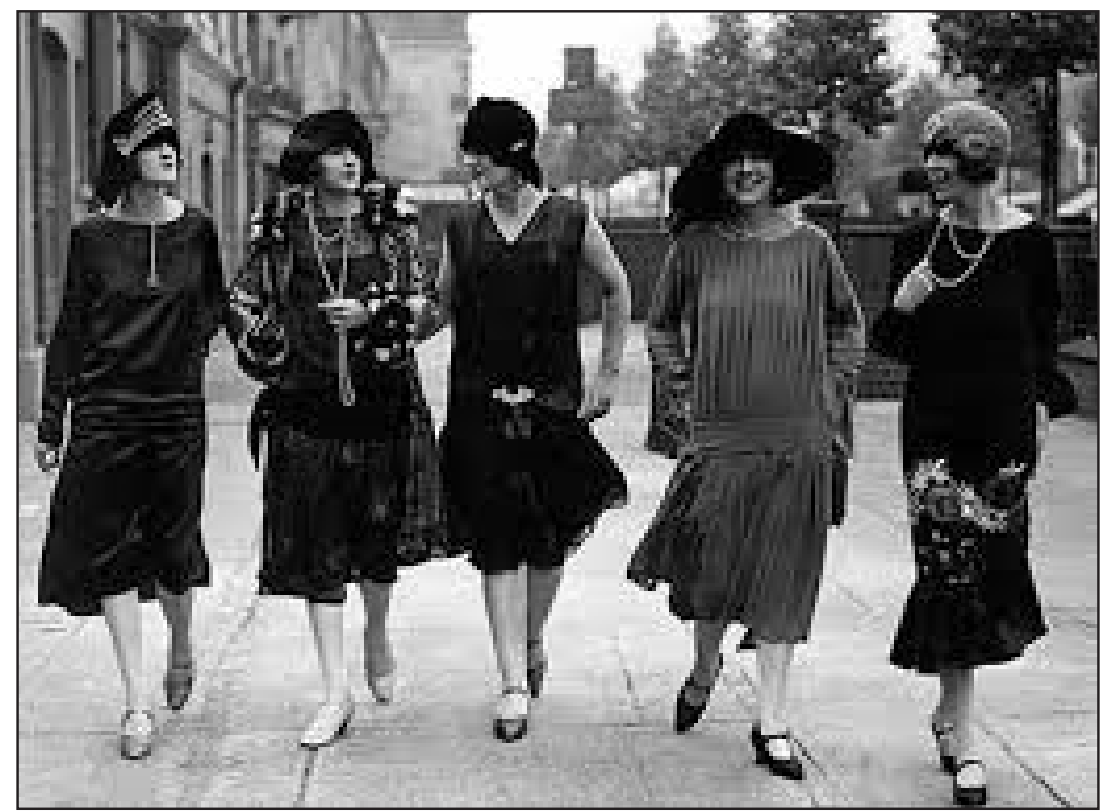

Mujeres flappers años 20

Por otro lado, la guerra impuso el modelo de la mujer garçonne producto de la contienda y de los años locos. Al disminuir la población masculina la mujer ocupó su posición y adquirió nuevas responsabilidades y un nuevo estilo. Pasó del estilo maduro y voluminoso propio de las matronas, a uno más juvenil y esbelto, con un cierto aire varonil, con el pelo corto como los hombres, vestidos sueltos de cintura baja, pieles blancas y boca pequeña. Surge un nuevo grupo de mujeres, denominadas "flappers". Eran las mujeres rebeldes de la época, con un fuerte deseo de liberación e independencia. Se conoce como la mujer roja, la mujer sexuada, la mujer carnal y liberada sexualmente, la mujer pasional, también la prostituta.

Finalmente, en medio de esta dualidad de percepción de las féminas hay otro tipo de mujer tremendamente estereotipado, la mujer negra. Se trata de la mujer que no puede cumplir el principal papel que le otorga la sociedad patriarcal, es decir, la reproducción. Por este motivo se le añade un carácter agrio, histérico y una apariencia fea, normalmente desagradable. Se le asocia con la figura de la suegra, la viuda, la 
monja, la bruja (Alario, 1995: 50). Este tipo de mujer también es asociado a aquellas mujeres independientes y liberadas que son fieles a sus principios y que no tienen en el sexo, (propio de la mujer roja), o en el hogar y la familia (propio de la mujer blanca) sus máximas aspiraciones.

Con todo lo expuesto podemos concluir que los estereotipos señalados nos muestran dos tipos claros de mujeres, las buenas y negociables (madres, esposas...) y las malas y consumibles (prostitutas, vampiresas...), dando mayor importancia a las primeras y quedando la mujer negra como un tertium genus, que en muchos casos se ha convertido en el contraestereotipo de la mujer patriarcal ya que ni es consumible, ni negociable, sino que se trata de una mujer independiente, no sujeta al varón, que apuesta por cultivarse y cree en ella misma y por estos motivos es desprestigiada y representada de manera antipática para provocar el rechazo social.

\section{Experiencias contraestereotípicas femeninas en el contexto de la Gran Guerra}

Para entender claramente nuestro objeto de estudio y poder hablar de los estereotipos y contraestereotipos del papel de la mujer en la Gran Guerra, es fundamental apoyarnos en la experiencia de varias mujeres coetáneas a este conflicto que sirvieron de inspiración para la realización de películas sobre su persona o que inspiraron el papel de las protagonistas o coprotagonistas de la mayoría de las películas que trataron la Gran contienda.

La PGM supuso el tránsito de la mujer victoriana, inmersa en la cultura patriarcal al inicio de la emancipación femenina que en los años veinte representó la mujer garçonne, a caballo entre la liberación sexual, el derecho al voto y la incorporación a la vida laboral y a la sociedad de consumo (Sohn, 1994:108).

En esta sociedad anclada en la cultura patriarcal surgen mujeres que rompen los estereotipos establecidos y que han servido de ejemplo para que muchas mujeres y la propia sociedad en general, hayan roto las cadenas victorianas que sumían a la mujer en los papeles binarios establecidos: o mujer ángel o mujer demonio. En este punto, recogeremos muy brevemente algunos ejemplos de estas mujeres que sirvieron de contraestereotipo a la sociedad patriarcal de su época, y que desde sus diferentes experiencias tuvieron el mérito de ser las precursoras en la introducción de la mujer en el espacio público y ayudar a conformar la sociedad actual tal como es hoy en día.

Es el caso de la doctora escocesa Elsie Inglis, una de las primeras mujeres que estudió medicina en Gran Bretaña y quien tuvo un importantísimo papel en la gran contienda en la creación de hospitales con personal femenino a través de una organización de mujeres financiada por movimientos sufragistas femeninos.

En este papel de mujer preparada encontramos a otras mujeres como Marie Curie, premio Nobel en 1911 quien junto a su hija impone la radiografía en la cirugía de guerra, ayudando considerablemente al acierto de los diagnósticos o Edith Cavell, enfermera británica que dirigía en Bruselas una fundación hospitalaria para los heri- 
dos de guerra y quien fue fusilada por los alemanes en 1915, acusada de espionaje (Thebaud, 1993: 62), entre otras muchas.

Otras mujeres como Louise Bryant que lideró las ideas sufragistas, sin embargo, pese a ser una reputada periodista y escritora, líder feminista y precursora de la liberación sexual, no es conocida por si misma, sino como compañera del periodista y político marxista John Reed. Como Bryant, muchas mujeres comienzan a destacar en la política a través de los movimientos sufragistas después de la gran Contienda, Mary Van Kleeck o Mary Anderson, intentan aplicar las nuevas teorías de la distribución del trabajo adaptando a las mujeres al mismo a través de las teorías del taylorismo.

Otras mujeres aprovecharon la entrada femenina al ámbito laboral masculino y por tanto su consiguiente masculinización, para romper los yugos del constructo estético femenino, liberando a las mujeres de los excesos ornamentísticos en el vestir. Dos figuras destacan en este aspecto, Coco Channel e Isadora Duncan, que supieron ser libres e independientes. Ambas representan la mujer-hombre peligrosa y desvergonzada, perversa congénita de aspecto y psiquismos masculinos, según los trabajos del psiquiatra alemán Krafft- Ebing (Thebaud, 1993: 43).

Finalmente, otros tipos de mujeres como Margarita Zelle (Mata-Harri), representan lo carnal, la liberación femenina a través de la mujer roja, consumible. Zelle para huir de la miseria aprovechó su físico y conocimientos de las danzas de Indonesia (donde vivió al ser colonia Holandesa), para frecuentar a hombres ricos, políticos y militares de ambos bandos. Es acusada de espionaje y fusilada en Vincennes en 1917. Ella lo negó y afirmó que se acostaba con militares por placer y no por deber, el halo de mujer perversa, contraestereotipo de la mujer virginal patriarcal.

\section{Estereotipos femeninos en el cine; especial referencia a las estereotipaciones femeninas en las películas sobre la Primera Guerra Mundial}

Como hemos indicado, los estereotipos de género son una forma de simplificar la realidad que se utiliza con reiteración en el cine. Desde sus orígenes el cine se ha nutrido de estereotipos sexistas, masculinos y femeninos, por lo que ya en la década de los setenta, se comenzó a analizar y clasificar los personajes femeninos en función de los estereotipos que representaban (Khun, 1991: 42). Pero, para estos primeros estudios, los estereotipos femeninos de los filmes representaban a mujeres y hombres que existían en la realidad, actuando las películas como un espejo donde se reflejaba esa realidad y donde se plasmaban los cambios femeninos en función de las transformaciones producidas en la sociedad (Haskell, 1974: 18).

En la actualidad, los estudios sobre género apuntan a que la imagen de la mujer y de la feminidad es una construcción cultural, creada por los discursos occidentales patriarcales que se ha plasmado históricamente en forma de dominación masculina y sujeción femenina (Bernad, 2012: 301). Este constructo culturalmente establecido, es 
arbitrario y simbólico y al estar incardinado fuertemente en nuestra sociedad cuesta mucho de deconstruir.

El estudio de los estereotipos de género en el cine se convierte en plataforma para expandir situaciones estereotipadas, y muchas veces discriminatorias, entre los sexos.

Siguiendo el método sociológico para analizar los estereotipos de género podemos señalar que los papeles que representa la mujer en el cine están relacionados a las funciones sexuales: mujeres vírgenes (mujer blanca) y mujeres vampiresas (mujer roja) que ya hemos analizado en el punto anterior.

En estos análisis, se hace hincapié en las distintas dimensiones donde se desenvuelven estos dos estereotipos de mujer. Por un lado el espacio privado, doméstico, el hogar, centro de la mujer ángel, la madre, hermana, esposa, novia ideal.... Por otro lado el espacio público, la esfera laboral, está ocupada por los hombres y por la mujer roja, malvada, vampiresa....Como se puede observar, los estereotipos femeninos se basan en el juego binario de imágenes positivas versus imágenes negativas.

En este sentido, y como ya hemos indicado, el cine narrativo clásico tiende a dividir el papel de las féminas en mujeres negociables (mujer blanca) y mujeres consumibles (mujer roja), colocando a las primeras por encima de las segundas y legitimando y transmitiendo los mismos roles que se representan socialmente en la cultura patriarcal.

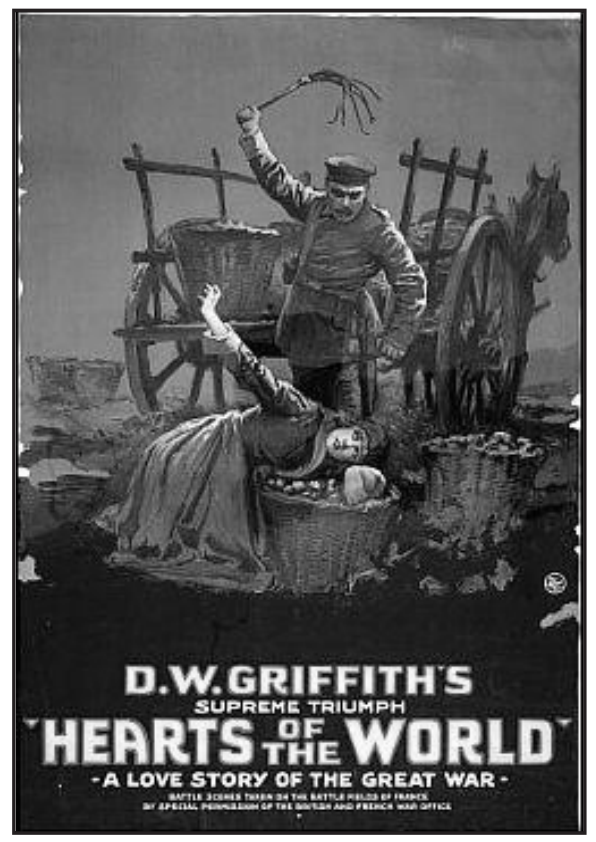

Cartel del film Corazones del Mundo (1918) de David W. Griffith
Estos estereotipos de género que se producen en la cinematografía general tienen su reflejo también en los papeles que desarrollan hombres y mujer sobre la Gran Guerra.

La mujer blanca, personaje femenino que representa el bien ligada a la ternura, sumisión, obediencia y docilidad entre otros, contrasta con los papeles masculinos que son activos, valientes, ambiciosos y protectores.

Estos personajes femeninos se asociaban imaginariamente a doncellas virginales e inocentes, normalmente deserotizadas, asediadas por malvados y enamoradas por héroes románticos que, a lo sumo, conseguían al final de innumerables peripecias un casto beso que sancionaba su amor. Este estereotipo derivado del folletín literario fue habitual, por ejemplo, en los filmes de uno de los más importantes directores del cine mudo: David W. Griffith (Benet, 2010: 286). 
Griffith realizó la película propagandística "Corazones del mundo" (1918) para apoyar la entrada de Estados Unidos en la PGM. Para su realización, Griffith visitó el frente buscando material, pero se sintió decepcionado por la falta de espectacularidad que le mostraba la realidad de las trincheras: suciedad, ratas y miedo. El director urdió un proceso de embellecimiento melodramático, fabricando una historia de amor convencional, bordeando los límites del ridículo, pero su poderosa formulación visual y la inclusión de las imágenes reales rodadas en el frente, la redime de gran parte de sus defectos.

En esta película, todos los estereotipos que rodean la mujer virginal se muestran con claridad, la novia que espera a su prometido, el traje blanco preparado para la boda, su abnegación, candor, inocencia...

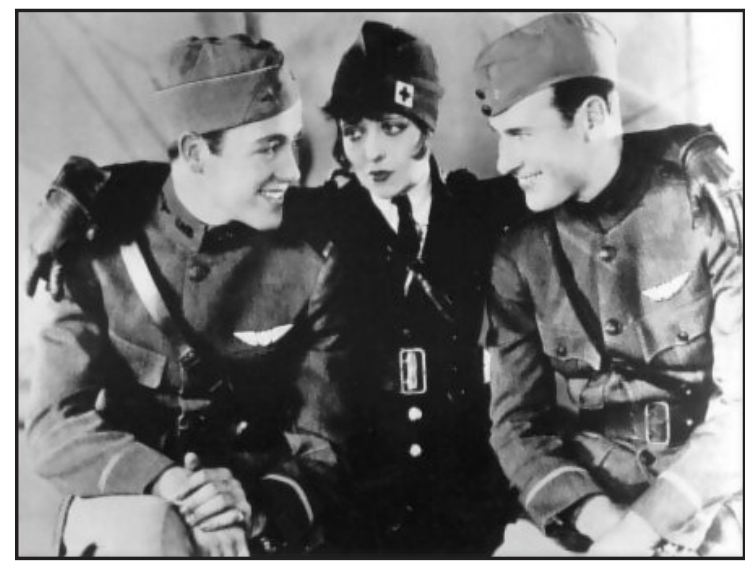

Fotograma del film Alas de 1927 de William A. Wellman

Otra película señera fue "Alas" 1927 de William A. Wellman. En esta película el estereotipo de la mujer abnegada, cuidadora y enamorada se nos muestra en el papel de una chica, humilde de barrio (Clara Bow), quien ama secretamente a uno de los protagonistas de la película, quien a su vez ama a otra mujer. Por este motivo, Mary decide alistarse como voluntaria enrolándose en el cuerpo sanitario americano, para hacer trabajos humanitarios en el frente, en cierto modo para saber que su enamorado, el piloto Jack Powel se encuentra bien. El papel de mujer angelical, que vela por su amor y es capaz de enfrentarse al peligro por él, contrasta con el acto de independencia por su parte al viajar al frente en medio del peligro.

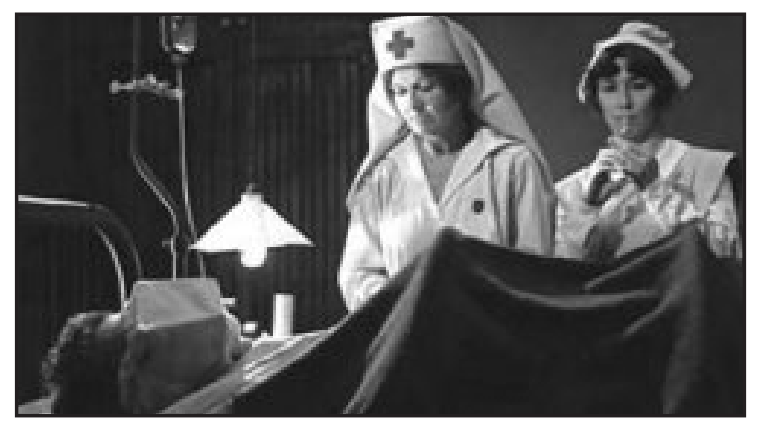

Fotograma del film Jhonny cogió su fusil (1971) de Dalton Trumbo

Otra película que nos permite analizar el papel protagonista de las enfermeras en esta contienda es "Johnny cogió su fusil" de Dalton Trumbo (1971). En ella un soldado tras la explosión de una bomba en el frente, se despierta en la cama de un hospital sin sentidos, es decir, ciego, sordo, mudo, además le faltan brazos y piernas. Está rodeado de médicos y enfermeras que lo observan y analizan, pero él no puede comunicarse con nadie, sólo puede pensar. Frente a los médicos militares fríos y distantes, las enfermeras 
muestran cariño, humanidad y empatía en el trato dispensado hacia el paciente, en especial el papel interpretado por Diane Varsi. Es ella quien logra comunicarse por primera vez con el paciente.

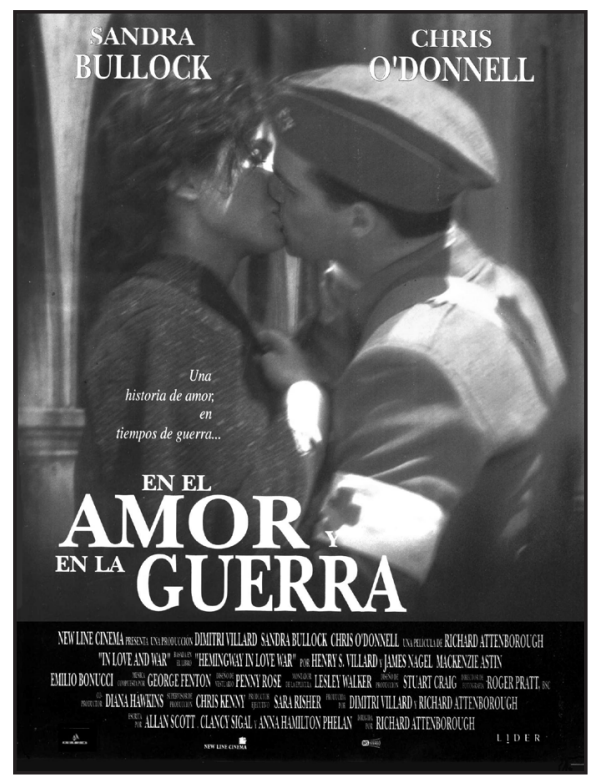

Cartel del film En el amor y en la guerra (1996) de Richard Attemborough
"En el amor y en la guerra" (1996) de Richard Attenborough, relata la historia real del romance surgido entre Ernest Hemingway con Agnes von Kurowsky, la enfermera que le cuidó y le atendió hasta que se repuso una devastadora herida sufrida en el campo de batalla.

En el film "La batalla de Passchendaele" (2008), Paul Gross, también se reproduce una historia ambientada en plena PGM. El Sargento Michael Dunne, un soldado que es gravemente herido en Francia, vuelve a Canadá para recuperarse y conoce en el hospital militar a Sarah (Carolina Dhavernas), una misteriosa y atractiva enfermera con quien mantendrá una apasionada historia de amor.

Encarnación de la abnegación, la enfermera, ángel y madre, es el personaje femenino más alabado de la guerra, tema preferido de los artistas bélicos. Pero a la vez,

sabemos poco de la naturaleza íntima del conflicto, y en este caso el cine nos muestra historias avaladas por testimonios, cartas e incluso índices indirectos, como las tasas de ilegitimidad durante el conflicto, o la explosión de divorcios al regreso de los soldados. Muchas de las películas analizadas nos muestran estos conflictos, la mujer blanca y pura, se transforma ante la guerra, y muestra otra cara. Es independiente,ostenta superioridad frente al enfermo (muchas veces los soldados heridos adolecen de educación y se sienten incómodos y distantes, frente a sus cuidadoras, quienes tienen el control de la situación). También estas mujeres, en muchos casos, están lejos de casa y solas, son dueñas de sus vidas y de sus actos por primera vez (Thébaud, 1993: 49).

En "Adiós a las armas" de Frank Borzage (1932), Catherine es una enferma británica que trabaja como voluntaria en el frente italiano. Allí conoce a Frederick, periodista norteamericano y conductor de ambulancias, ambos se enamoran y pese a la distancia e independencia de su situación, se casa y queda embarazada. En este caso, el estereotipo se repite y pese a la independencia que gozaba Catherin, se convierte fácilmente en mujer negociable, mujer blanca, el estereotipo de mujer a seguir.

Por otro lado, otro estereotipo de la época, es ampliamente utilizado en las películas sobre esta contienda, la femme fatale y sus derivaciones (vamp, mujer pasional, 
mujer exótica o primitiva). Esta mujer que representa lo exótico y carnal, significa lo prohibido, lo malo. Un ejemplo real que luego la filmografía ha recogido con cierta profusión es el caso de Mata-Hari Su figura inspiró un montón de películas e historias, destacando "Mata-Hari" (1931) de George Fitzmaurice, protagonizada por la gran Greta Garbo.

Otros personajes femeninos rojos en las películas con temática alrededor de la gran contienda son las flappers. Realmente surgen en el periodo del liberalismo posterior a la PGM pero tienen su precedente en las Gibsons Girls de principios del siglo XX que representaba la belleza, la moda y el éxito social, y que son consideradas como las primeras Pin-ups. Las Gibson Girls fueron el primer modelo de belleza estadounidense y tienen su más claro reflejo cinematográfico en la Rose DeWitt Bukater, de la película "Titánic" (1997) de James Cameron. Rose reúne todas las características que representa este modelo de mujer, bella, elegante, culta y con deseos de independencia, aunque siendo consciente de su deber como hija, ya que sacrifica sus ansias de libertad y amor con un matrimonio concertado de interés, para que su familia puedan mantener su estatus social. La acción transcurre en 1912, un año y medio antes de la Gran contienda, pero en la película ya se puede mascar los preparativos de la guerra.

La guerra transformó a las mujeres, sobre todo las dotó de un ansia de independencia como nunca antes en la historia habían tenido. Cuando vuelven a sus casas, ya no quieren encerrarse en el ámbito privado familiar, anhelan salir al espacio público, trabajar, viajar, educarse. Son las flappers o las garçonnes, mujeres que no abandonaban sus estudios y querían ser ellas las que escogieran su pareja. Eran sanas, incluso deportistas, seguras de sí misma, pero sin ostentación, sonreían con frecuencia, pero no solían reír, manteniendo siempre una cierta distancia.

De esta manera, la imagen de la mujer sufre un cambio en la filmografía que se corresponde con un rápido cambio social en la sociedad americana (Marzal, 1998: 145). El ideal de mujer victoriana, sumisa y heroína virginal que representaba Mary Pickford (entre otras) y Griffith como director, pasa a otro tipo de mujer liberada y con un comportamiento escandaloso y picante que representaba las películas del director John Collins y la actriz Viola Dana.

Este tipo de féminas, tienen su reconocimiento, en las películas de cine sobre la Gran Guerra, como el patrón de la mujer roja, construida como un ser carnal y plenamente sexualizado. Se relaciona con el poder destructor de las pulsiones eróticas, la preeminencia del instinto y la quiebra de los elementos que sostienen el orden social.

Según Benet (2010: 297) este patrón maniqueo de los años 10, con las mujeres tipo Gibson Girls, comenzará a disolverse hacia los años 20, en los que se construye el imaginario de una mujer moderna o moderadamente desinhibida (flapper, la gamine chaplinesca) que integra algunos de los aspectos de los dos modelos de partida, mujer negociable/mujer consumible. Aunque presente una contención de los impulsos y un cierto pudor en su actitud sobre la que se constituye su carácter de objeto de deseo para el personaje masculino, tiene también aspectos agentes para el desarrollo de la trama y sobre todo posee rasgos marcadamente sexualizados. 
En la película "Rojos" (Warren Beauty, 1981), Louise Bryant, compañera y luego esposa del protagonista Reeds, se nos muestra como una inquieta mujer que luchaba por su emancipación y por triunfar como escritora. Abandonó a su marido, y se fue a vivir con el periodista Reed, integrándose en un grupo de intelectuales activistas de izquierdas. Esta figura representa valores como libertad, independencia, feminismo, pacifismo, librepensamiento y libertad sexual.
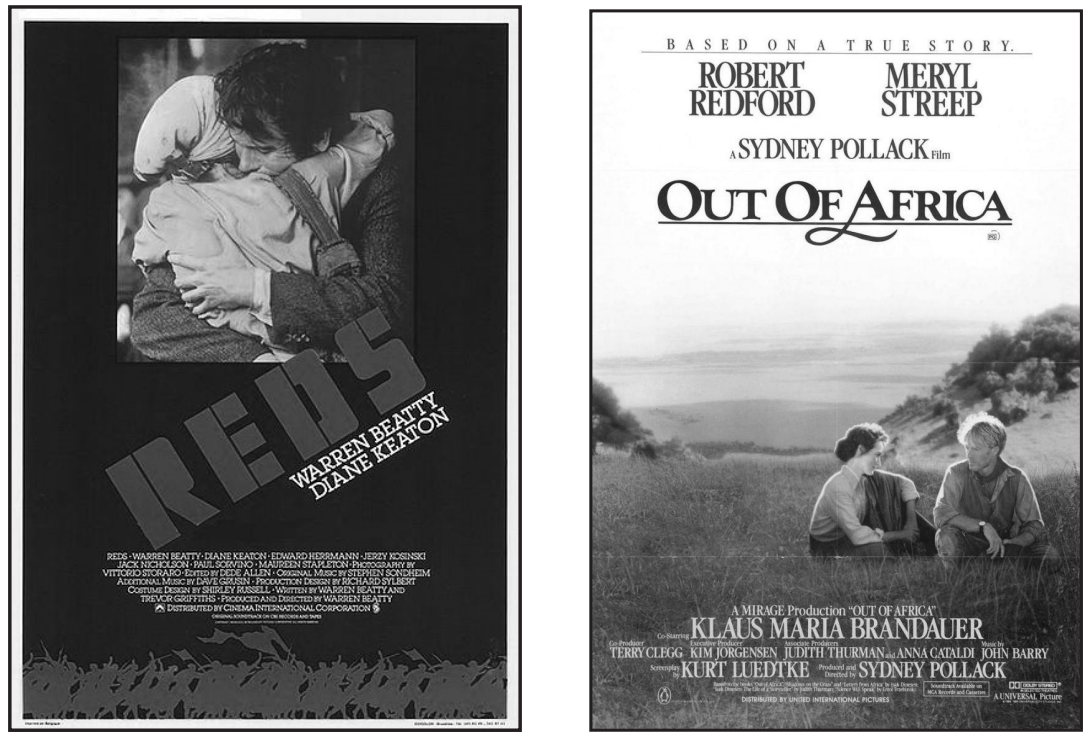

También en la película Memorias de África (Sidney Pollack, 1985), se nos muestra un tipo de mujer educada, independiente, decidida y con valores que en la época de la Gran contienda, eran atribuidos a los hombres. Karen, la protagonista que figura inspirada en la escritora Isack Dinesen, cumple con todos las exigencias de una mujer de su época y posición, matrimonio por conveniencia, seguir al esposo, ocultar sus infidelidades; pero poco a poco los acontecimientos hacen que cambie su actitud.

Finalmente, la mujer negra, reflejada en las películas sobre la gran contienda, se encuentra representada por las mujeres reaccionarias y ultraconservadoras, que se oponían a los movimientos sufragistas de principios de siglo y durante la guerra y posteriormente las mujeres que encarnaban la nueva revitalización religiosa tras el crack del 29, que erradicó los estilos de vida liberal y las modas de los años locos.

Este tipo de mujer suele tener una imagen amargada debido a que ya no puede cumplir su papel principal como mujer: la procreación. Por este motivo suele mostrar un carácter agrio e intolerante, recordando el papel de las brujas de los cuentos.

En la película Mary Popins, (Robert Stevenson, 1964), una familia burguesa londinense en el preludio de la contienda (1910) cuenta con una madre sufragista que es 
reprendida por la vieja niñera quien encarna los valores de la mujer negra, vieja, amargada y fea.

\section{Conclusiones}

La PGM supuso un cambio fundamental para la mujer y su implicación en la esfera pública laboral. Esta incursión necesaria en la época del conflicto sentó un precedente social importantísimo en las relaciones de género y aunque la situación extraordinaria del tiempo de la guerra fue superada, la mujer ya no dudó de su valía laboral, y empezó a nutrir con fuerza y dinamismo el espacio público reservado hasta entonces al género masculino.

Ciertamente, el camino no fue fácil, los estereotipos heredados de épocas precedentes se siguieron manteniendo tras la Gran Guerra, pero poco a poco cambiarán las actitudes y los arquetipos de referencia. Tras el conflicto armado, dos consecuencias hacen que aparezca un nuevo tipo de mujer liberada y trabajadora: las flappers. Por un lado, el liberalismo que empieza a surgir imponiéndose en el mercado, este estilo de mujer moderna, las flappers, grandes consumidoras, apuestan por el ocio, el deporte, la lectura, los viajes y la moda, marcando un estilo de vestir y de vivir, imborrable en la historia. Por otro lado, este tipo de mujer no hubiese sido posible sin la experiencia de la guerra, que supuso la incorporación de la mujer al mercado laboral, en el frente y en la retaguardia, dotando a la mujer de independencia económica, y en ciertos aspectos, de independencia social.

Además, un nuevo factor irrumpe en ese contexto, la aparición del cinematógrafo. La retransmisión del conflicto de primera mano, a través de los documentales, y la interpretación melodramática de los acontecimientos que acaecen tanto en las trincheras como en la retaguardia, establecen arquetipos masculinos y femeninos, que consolidan los históricos estereotipos establecidos para ambos sexos. Frente al hombre héroe, valiente y cortes, la mujer sigue presentándose como mujer blanca, roja o negra. Es decir, la mujer angelical, virgen, pura, madre, reconocida en las hermanas, sumisas novias y esposas de soldados en el frente, dulces enfermeras o sufridas madres entre otras. La mujer roja, voluptuosa, sexuada, carnal o prostituta, que disfruta con independencia de su cuerpo y que es la perdición o trampa de muchos hombres buenos que caen rendidos a sus pies, son mujeres liberadas, independientes, guapísimas y en la mayoría de los casos, mujeres solas. Finalmente la mujer negra, que representa aquellas mujeres que buscan volver al tiempo perdido, mujeres conservadoras, celosas de su espacio privado, religiosas y severas, normalmente feas y ariscas, que reflejan papeles como las suegras y viudas, aquellas mujeres entradas en una edad, que no pueden procrear y por tanto son estigmatizadas, no cumplen su rol social y que literariamente comparaban a las brujas.

Pero pese a estos arquetipos claramente establecidos, existen otros tipos de mujeres que se salen de esta clasificación, mereciendo un reconocimiento a parte. Estas 
mujeres que el cine nos ha ayudado a no olvidar y que humanizan aquella época en la que se podía ser mujer blanca, a la par que roja o negra.

En este sentido, el cine de la gran contienda supone por un lado representar el reflejo de la presencia de la mujer en la sociedad de aquella época, pero por otro lado, también impone, el nuevo modelo de mujer que surge por las especiales circunstancias de este conflicto y que transforma de manera unívoca el constructo femenino del siglo XX. De esta forma, aunque todavía inmersas en la cultura patriarcal, el cine de la gran contienda, inspiró a través de muchas de sus protagonistas, un nuevo papel para la mujer del siglo XX, más moderna, independiente tanto económica como sexualmente, apartando tapujos y barreras propios de la decimonónica sociedad victoriana.

Finalmente, pese a que la PGM significó un cambio en la situación social de la mujer, incorporándola paulatinamente al mercado laboral y al espacio público, esta nueva mujer moderna, comparte con la doncella virginal el hecho de convertirse en un objeto de deseo para el personaje masculino que arrastrará la trama y el definirse de acuerdo con un cierto recato, pero por otro lado, comienza a definirse como una figura sexualizada, que es capaz de transmitir sus impulsos eróticos y que tiene un cierto carácter agente en el desarrollo de la trama (Benet, 2010: 297).

Es decir, el cine siguió y sigue representando esquemas estáticos propios de la cultura patriarcal, que repite reproduciendo los arquetipos en los que la mujer ha sido simbolizada y sigue siendo simbolizada, distinguiendo entre dos tipos claros de mujeres, las buenas y negociables (madres, esposas...) y las malas y consumibles (prostitutas, vampiresas...), y dando, no obstante los nuevos constructos culturales, mayor importancia a las primeras.

\section{Bibliografía}

ALARIO, M.T. (1995) “La mujer creada. Lo femenino en el arte occidental”. Revista UCM.http://revistas.ucm.es/bba/11315598/articulos/ARIS9595110045A.PDF. Captura 29- junio- 2013.

ARNAUD-DUC, N. (1994), "Las contradicciones del derecho" El siglo XIX, Historia de las mujeres $I V$, Santillana, S.A., Barcelona.

BENET FERRANDO, V. (2010) "Claves para romper con los estereotipos femeninos en el cine y la televisión”, Igualdad de Género en el ámbito público y privado, F. ISONOMIA, Universitat Jaume I, Castellón.

BERNAD, E. (2010) «Ilicitud de las representaciones degradantes y humillantes del cuerpo femenino en la publicidad: Especial referencia a la anorexia ». En Icono 14.0

BERNAD, E. (2010) La influencia de la publicidad en la conformación de la imagen de las mujeres. Desde el punto de vista jurídico. En Igualdad de género en el ámbito público y privado. VV.AA. Castellón, Fundación Isonomía, pp. 301-320. 
BERNAD, E. (2012). Alfabetización mediática: Incardinación de la perspectiva de género a través del estudio de los nuevos formatos publicitarios televisivos". Innovar en el EEES a través de la investigación. Visión libros. Madrid.

BEAUVOIR, S. (1998) El segundo sexo, Cátedra, Madrid.

BUSTOS, O. (2004) "Políticas públicas, medios de comunicación y formación de audiencia crítica con enfoque de género", Mujer y desarrollo en el siglo XXI: Voces para la igualdad ( $\mathrm{M}^{\mathrm{a}}$ Angeles Reboolo y e Inmaculada Mercado), Ed. Mc Graw Hill, Madrid.

CAMPS, A. (2011) "Lilith o Beatrice: la mujer en el Fin de siglo. Arquetipos femeninos dannunzianos y su difusión en el Modernismo" Revista internacional de cultura y literatura. Grupo de investigación escritoras y escrituras. http://www. escritorasyescrituras.com/revista.php/10/78. Captura 29- junio- 2013.

COBO, R. (1995), “Género" Diez Palabras clave sobre Mujer Dra. Celia Amorós. Edit. Verbo Divino. Pamplona.

ELOSEGUI, Maria Video-estudio, Universidad de Zaragoza, "Los Roles de la Mujer en la Publicidad". 1996. Zaragoza.

ELOSEGUI, M. (1998). «Igualdad y diferencia mujer-varón según el tribunal Constitucional español. Especial referencia a la interpretación en el ámbito laboral», pag. 80, en mujeres y Derecho, coordinadora Paloma Durán Lalaguna, Edit. Ajuntament de Valencia. Valencia.

FERRÚS I BATISTE, J (2010) "Las mujeres en la historia", Igualdad de Género en el ámbito público y privado, F. ISONOMIA, Universitat Jaume I, Castellón.

HASKELL, M. (1987). From Reverence to Rape: The Treatment of Women in the Movies. Chicago: University of Chicago Press.

HIGONNET, A. (1994): "Las mujeres y las imágenes. Apariencia, tiempo libre y subsistencia" El siglo XIX, Historia de las mujeres IV, Santillana, S.A., Barcelona.

KHUN, A. (1991). Cine de mujeres: feminismo y cine. (S. Iglesias Recuero, Trad.). Madrid: Cátedra.

LERDA, G.(1984) «The Challenge of Women's History», The Majoríty finds its Past. Placing Women in History, Nueva York (traducción española de Mary NASH en Presencia y protagonismo. Aspectos de la historia de la mujer, Barcelona.

MARZAL, J (1998), David Wark Griffith, Ediciones Cátedra S.A., Madrid.

ROMERO, E.G. (2013), La Primera Guerra Mundial en el cine. El refugio de los canallas. T\&B Editores. Madrid.

SOHN, A.M. (1994), "Los roles sexuales en Francia e Inglaterra: una transición suave", El siglo XX, Historia de las mujeres en occidente V (Perrot), Santillana, S.A., Barcelona.

SOTELO, R (2011), "La introducción de la mujer en el mundo laboral ¿Fue una decisión de la mujer?" Revista Digital de Humanidades. Universidad de la Marina Mercante. Disponible en http://redh-udemm.blogspot.com.es/2011/08/la-introduccion-de-la-mujer-en-el-mundo.html. Captura 1 de agosto de 2013.

THÉBAUD, F., DUBY, G., PERROT, M. (1993), "La Primera Guerra Mundial: ¿La era de la mujer o el triunfo de la diferencia sexual" El siglo $X X$, Historia de las mujeres en occidente V (Perrot), Santillana, S.A., Barcelona. 


\section{Los autores}

Estela Bernad Monferrer es Licenciada en Derecho por la Universidad de Valencia y Doctora en Comunicación por la Universitat Jaume I. Es profesora del Departamento de Ciencias de la Comunicación, y del Máster en Nuevas tendencias y Procesos de Innovación en Comunicación y del Máster Igualdad y Género en el ámbito Público y Privado de la Fundación Isonomía y distintas Universidades españolas y latinoamericanas. Pertenece a distintos grupos de investigación sobre Género, Intangibles, Citymarketing y Protocolo.

Magdalena Mut Camacho es Doctora en Comunicación empresarial e institucional por la Universitat Jaume I y licenciada en Ciencias de la información por la UAB. Profesora del Departamento de Ciencias de la Comunicación y del Máster Oficial en Nuevas Tendencias y Procesos de Innovación en Comunicación de la UJI. Es co-directora con Joan Costa del Máster Internacional de Dirección y Gestión de la Comunicación. Su docencia e investigación se centra en la gestión intangible de la organización y en la comunicación corporativa. Ganadora del I Premio Prat Gaballi. Dirige el grupo de investigación Reputation, Brand and Innovative Communication Towards Competitiveness.

César Fernández Fernández es Doctor en Comunicación por la Universitat Jaume I de Castellón. Licenciado y DEA por la Universitat de València en Comunicación Audiovisual. Es Profesor del Departamento de Ciencias de la Comunicación de la Universitat Jaume I de Castellón. Igualmente es profesor en la UJI del Master en Nuevas Tendencias y Procesos de Innovación en Comunicación y del Master Universitario Internacional en Estudios de Paz, Conflictos y Desarrollo. Forma parte del grupo de investigación ITACA (Investigación en Tecnologías Aplicadas a la Comunicación Audiovisual) y del grupo de investigación Periodismo, Comunicación y Poder, ambos de la UJI. Es investigador de comunicación en el Grupo de Investigación DATS del INTRAS (Instituto Universitario de Tráfico y Seguridad Vial) de la UV. 